\title{
Letters
}

\section{Early intervention for first episode psychosis}

\section{Secondary care must become more responsive to primary care}

EDITOR-Shiers and Lester observe that primary and secondary care must work together and that the wider involvement of the community is the key to success. However, they eschew a more detailed appraisal of these important issues in favour of a finger wagging at general practice.

They base their predication on several assumptions. Firstly, they assume that general practitioners neither recognise early psychotic features nor wish for involvement in managing mental health. Secondly, they assume that people with psychotic symptoms want to see psychiatrists or wish to take medication commonly believed to have unpleasant side effects. Finally, they assume that secondary care is responsive to the concerns of primary care workers and patients alike. Little of the above holds true. As a result of recent pressure from the government (and in many cases, well before this), primary care is remarkably responsive to patients' demands. Most general practitioners are wholly familiar with mental health problems, and so the issue is not one of training, it is about the negotiation between health profes-

sional, patient, family, and secondary care. The London borough of Tower Hamlets is home to large numbers of non-English speakers. A general practitioner who recognises psychotic features has to persuade the patient and his or her family that a trip to the local psychiatric hospital is in the patient's best interests, in order to involve the community mental health team, which will not accept referrals from general practitioners unless a diagnosis of psychosis has been made. This is antediluvian practice, and, although it may be a local problem, it is essential that community mental health teams work more closely with primary and secondary care if early intervention for first episode psychosis is to be a success. The new government programme for the expansion of primary care premises is an ideal opportunity to bring psychiatric services into the community.

James N Hardy general practitioner principal Bethnal Green Health Centre, London E2 6LL james.hardy@nhs.net
Competing interests: None declared.

1 Shiers D, Lester H. Early intervention for the first episode of psychosis. BMJ 2004;328:1451-2. (19 June.)

Consider increasing staff at primary care level before complaining

EDITOR-Much has been written regarding awareness or the lack of it in mental health issues, as a major factor in the degree of general practitioners' involvement in the care of their patients with mental health problems. Although the article by Shiers and Lester ${ }^{1}$ rightly identifies the importance of primary care involvement, professionals in the secondary and tertiary care settings should not lose sight of the fact that, although they deal with disorders confined to a particular physiological system and exhort the need to adhere to national service frameworks and evidence based consensus guidelines, general practitioners have to deal with the entirety of the patient's health.

The traditional health-

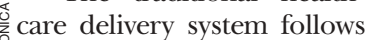
an inverted funnel distribution, with expansion of services at secondary and tertiary levels. To facilitate greater 옿 involvement of primary care professionals in mental health, consideration must be given to increase the skilled manpower at this level rather than complain of poor engagement by them. This would have the added benefit of services being available to patients within the primary care setting and reduce the stigma attached to mental illness.

Prem K Kunjukrishnan specialist registrar in old age psychiatry

pk.kunjukrishnan@ntlworld.com

Lekshmi Premkumar currently unemployed

Dewsbury and District Hospital, Dewsbury WF13 4HS

Competing interests: None declared.

1 Shiers D, Lester H. Early intervention for the first episode of psychosis. BMJ 2004;328:1451-2. (19 June.)

Worldwide burden of psychosis is not as severe as suggested

EDITOR - I found the editorial by Shiers and Lester on early intervention in psychosis insightful and practical. ${ }^{1}$ However, it contains an important error. The authors say that worldwide, the burden of psychosis is exceeded only by quadriplegia and dementia. Although there can be no doubt that schizophrenia is a disabling condition with an early onset, it does not cause the degree of global burden in terms of disability adjusted life years (DALYs) or years of life lost though illness as many chronic conditions. Psychosis ranks 22nd in the worldwide causes of disability (or 12th, if high income counties are considered alone) according to the World Health Organization's 1999 study into the global burden of disease. ${ }^{2}$ The comparable rates for unipolar major depression are fourth and second, respectively. The figures that Shiers and Lester quote are derived from people's perception of disease burden calculated by WHO's Assessment Classification and Epidemiology Group. ${ }^{3}$ In this study 241 key informants (health professionals, policy makers, people with disabilities, and their carers) from 14 countries were asked to rank 17 health conditions from most disabling to least disabling, but not necessarily taking into account prevalence. The result was by no means identical to the global burden of disease study.

Alex J Mitchell consultant in liaison psychiatry Leicester General Hospital, Leicester LE5 4PW alex.mitchell@leicspart.nhs.uk

Competing interests: None declared.

1 Shiers D, Lester H. Early intervention for the first episode of psychosis. BMJ 2004;328:1451-2. (19 June.)

2 World Health Organization. World health report 1999. Chapter 2: The double burden: emerging epidemics and persistent problems. www.who.int/whr2001/2001 archives/1999/en/pdf/chapter2.pdf

3 Ustun TB, Rehm J, Chatterji S, Saxena S, Trotter R, Room $\mathrm{R}$, et al. Multiple-informant ranking of the disabling effects of different health conditions in 14 countries. WHO/NIH Joint Project CAR Study Group. Lancet 1999;354:111-5.

\section{Paediatrics has a role too}

EDITOR-Shiers's and Lester's review should have mentioned the role of acute paediatrics in picking up young people with psychosis. ${ }^{1}$ It is not common but occasionally we meet quite ill but puzzling teenagers who need a multidisciplinary assessment to tease out organic, social, and psychiatric factors before we can work out what precisely is the matter. This requires a team of social workers and child and adolescent psychiatrists working with the paediatric staff, as recommended in the hospital national service framework for children. $^{2}$

Sebastian Kraemer consultant child and adolescent psychiatrist

Whittington Hospital, London N19 5NF

sebastian@kraemer-zurne.freeserve.couk

Competing interests: None declared. 
1 Shiers D, Lester H. Early intervention for the first episode of psychosis. BMJ 2004;328:1451-2. (19 June) 2 Department of Health. Getting the right start: national serv-
ice framework for children: standard for hospital services. London: DoH, 2003. www.dh.gov.uk/PublicationsAnd Statistics/Publications/PublicationsPolicyAndGuidance/ PublicationsPolicyAndGuidanceArticle/fs/en?CONTENT $\mathrm{ID}=4082169 \&$ chk $=$ qvLhif $($ accessed $28 \mathrm{Jul} 2004)$.

\section{Helicobacter pylori and gastro-oesophageal reflux disease}

\section{Information on underlying pathology is not given}

EDITOR-We read with interest the article by Harvey et al on the effects of Helicobacter pylori infection on heartburn and gastro-oesophageal reflux. ${ }^{1}$ However, as the authors recognise, the mechanism by which $H$ pylori infection might affect reflux symptoms is by altering secretion of gastric acid, due to the $H$ pylori related antral gastritis which results in a net increase in acid secretion. ${ }^{2}$ Nevertheless, a number of recent studies, by combining old and new diagnostic tools (such as $\mathrm{pH}$ monitoring, bilimetry, and intraluminal oesophageal impedance), are providing a new and more detailed characterisation of the factors contributing to the so called gastro-oesophageal reflux disease. $^{3-5}$

As Harvey et al recognise, their study has some weaknesses, due to the absence of direct information on the pathology underlying the symptoms of the patients, and one of these is that a subset of the enrolled patients might have reflux symptoms due to the occurrence of non-acid or non-liquid reflux events. This may possibly lead to an underestimation of the real role of $H$ pylori in the pathogenesis of acidrelated heartburn and gastro-oesophageal acid reflux.

Giovanni Cammarota assistant professor gcammarota@rm.unicattit

Giovanni B Gasbarrini senior lecturer

Unit of Gastroenterology; Catholic University

Hospital, largo A. Gemelli, 8-00168, Rome, Italy

Competing interests: None declared.

1 Harvey RF, Lane JA, Murray LJ, Harvey IM, Donovan JL, Nair P. Randomised controlled trial of effects of Helicobar pylorinfection a Helicobacter pylori infection and its eradication on heart-
burn and gastro-oesophageal reflux: Bristol helicobacter burn and gastro-oesophageal
project. $B M I 2004 ; 328: 1417-9$.

project. BMJ 2004;328:1417-9.
2 El Omar EM, Penman ID, Ardill JE, Chittajallu RS, Howie

2 El Omar EM, Penman ID, Ardill JE, Chittajallu RS, Howie
C, McColl KE. Helicobacter pylori infection and abnormalities of acid secretion in patients with duodenal ulcer disease. Gastroenterology 1995;109:681-91.

3 Tack J, Koek G, Demedts I, Sifrim D, Janssens J Gastroesophageal reflux disease poorly responsive to single-dose proton pump inhibitors in patients without Barrett's esophagus: acid reflux, bile reflux, or both? $A m J$ Gastroenterol 2004:99·981-8.

4 Kawamura O, Aslam M, Rittmann T, Hofmann C, Shaker $\mathrm{R}$. Physical and $\mathrm{pH}$ properties of gastroesophagopharyngeal refluxate: a 24-hour simultaneous ambulatory impedance and pH monitoring study. Am J Gastroenterol 2004; ance and $\mathrm{pH}$
5 Shay S, Tutian R, Sifrim D, Vela M, Wise J, Balaji N, et al. Twenty-four hour ambulatory simultaneous impedance and $\mathrm{pH}$ monitoring: a multicenter report of normal values from 60 healthy volunteers. Am J Gastroenterol 2004;99: $1037-43$.

\section{Important data were not presented}

EDITOR-The paper by Harvey at al shows several inconsistencies. ${ }^{1}$ The first line contains an error: most patients with Helicobacter pylori actually have a mild pangastritis with normal or decreased intragastric acidity; the antral inflammation stimulates hypergastrinaemia but is balanced by a relative suppression of acid secretion by the oxyntic body, and duodenal ulcer occurs in only $10 \%$ of infected patients. $^{2}$

The authors seem confused as to whether they are assessing gastrooesophageal reflux disease, as claimed, or occasional symptoms. The prevalence of symptoms once a month, the authors' definition, is very high and may not be pathological. Authorities propose that heartburn twice a week is a more reasonable definition of reflux disease. ${ }^{3}$

If the study was designed to address the question of $H$ pylori and reflux the structure is suboptimal. Well validated questionnaires designed specifically for reflux symptoms are available. ${ }^{4}$ Reflux is more severe in elderly people, ${ }^{45}$ and by excluding people over 60 Harvey et al may not have studied those most at risk. The authors used a questionnaire, but there is no evidence that this has been validated against reliable measures of gastro-oesophageal reflux disease such as endoscopic Los Angeles scoring or ambulatory oesophageal $\mathrm{pH}$ monitoring. All these issues are important when comparing this paper with the others cited that have used much more objective diagnoses of the disease.

Harvey et al discuss the pathophysiology of the infection, but the important data relating $H$ pylori clearance, as opposed to intending eradication, to reflux have not been presented.

Ian L P Beales senior lecturer

Norfolk and Norwich University Hospital NHS Trust, Norwich NR4 7TJ

ian.beales@uea.ac.uk

\section{Competing interests: None declared.}

1 Harvey RF, Lane JA, Murray LJ, Harvey IM, Donovan JL, Nair P. Randomised controlled trial of effects of Helicobacter pylori infection and its eradication on heartburn and gastro-oesophageal reflux: Bristol helicobacter burn and gastro-oesophageal

2 Beales I. The H. pylori-gastrin link. In: Merchant JL, Buchan AM, Wang TC, eds. Gastrin in the new millennium Los Angeles: CURE Foundation, 2004:253-63.

3 Dent J, Brun J, Fendrick AM., Fennerty MB, Janssens J Kahrilas PJ, et al. An evidence-based appraisal of reflux disease management-the Genval workshop report. Gut 1999;44:S1-S16.

4 Diaz-Rubio M, Moreno-Elola-Olaso C, Rey E, Locke GR, Rodriguez-Artalejo F. Symptoms of gastro-oesophageal reflux: prevalence, severity duration and associated factors in a Spanish population. Aliment Pharmacol Ther

5 Collen MJ, Abdulian JD, Chen YR. Gastroesophageal reflux disease in the elderly: more severe disease that reflux disease in the elderly: more severe disease that
requires aggressive therapy. Am J Gastroenterol requires aggres
1995;90:1053-7.

\section{Stigma, shame, and blame experienced by patients with lung cancer}

\section{Health promotion and support groups} have a role

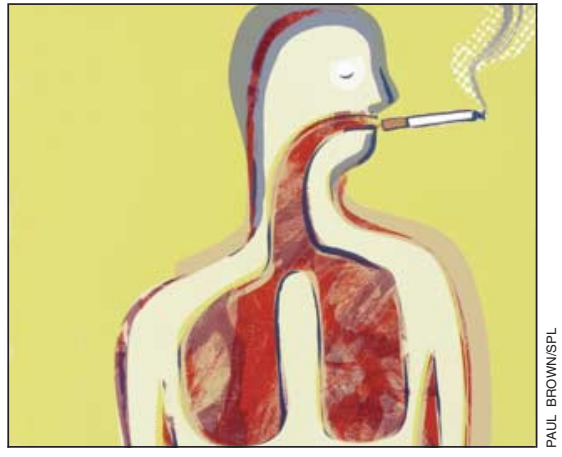

EDITOR-The research article by Chapple et al highlights problems for lung cancer patients and their experiences of stigma and shame bring to mind two allied factors. ${ }^{1}$

Health promotion strategies have increased with our identification of chronic conditions as the major health threat. The role of industrial development in exacerbating chronic health issues was implicated, and initially health promotion advocates contextualised illness with environmental, psychological and socioeconomic factors. ${ }^{2}$ Unfortunately the "determinants of health" model was often viewed as damaging to economic interests and a more "watered down" individual version was preferred. ${ }^{3}$

However, many people (especially those in lower socioeconomic groups) have fewer experiences of personal agency and greater difficulty changing unhealthy behaviours. ${ }^{4}$ Thus individualised health promotion strategies have worked more effectively for people in higher socioeconomic groups. ${ }^{3}$ The individualised model of health promotion has created a society that internalises the connection between choice, behaviour and health but reacts by "blaming the victim." This phenomenon is ubiquitous in social and psychological literature including attitudes to illness. ${ }^{5}$ Consequently patients experience further isolation, creating depression or anxiety, which affects quality of life and possibly increased morbidity.

Support groups have been found to be valuable to increase quality of life and experiences of patient agency. In this study participants who attended support groups discussed their feelings of shame but were more aware of the partial culpability of tobacco companies in product promotion. This "resistance" to the stigmatisation might also be seen as a resistance to the individualisation of their illness.

Rory Coughlan assistant professor of health psychology Trent University, 1600 West Bank Drive, Peterborough, Ontario, Canada K9J 7B8 rorycoughlan@trentu.ca

Competing interests: None declared.

1 Chapple A, Ziebland S, McPherson A. Stigma, shame, and blame experienced by patients with lung cancer: qualitative study. BMJ 2004;328:1470. (19 June.) 
2 Mustard JF, Frank J. The determinants of health Toronto: Canadian Institute for Advanced Research, 1991.

3 Townson M. Health and wealth: how social and economic factors affect our well-being. Toronto: Canadian Centre for

4 Coughlan R. Agency communication and embodiment. Using Using qualitative research to explore healthcare relation-
ships. Psychol Health 2004 (in review).

Bittman B, DeFail A. Reprogramming pain:transforming pain and suffering into health and success. Meadville, PA

\section{Non-smoker status should also be declared}

EDITOR-I write with reference to the article by Chapple et al on the negative experiences of patients with lung cancer. ${ }^{1}$ I remember a campaign many years ago encouraging doctors to record on a patient's death certificate that a smoking related death was due to smoking. ${ }^{2}$ Several years ago my father was diagnosed with lung cancer. He was a non-smoker and not even a passive smoker.

In the months leading up to his death I became concerned that in years to come people seeing his death certificate in the archives would assume that he died because of smoking. This upset me.

After his death I asked the doctor providing the death certificate to state on the form that my father was a non-smoker. This was done. I had one hurdle left. I am pleased to say that the registrar of births and deaths accepted the death certificate as it was written along with the comment that my father was a non-smoker. This helped me greatly in the days after my father's death.

If doctors are to be encouraged to record on a death certificate that a patient was a smoker then I think it is only fair that the opposite can be appended as well.

Keith A Walters consultant in accident and emergency medicine

Norfolk and Norwich University Hospital, Norwich NR4 7UY

Kawmeadow@aol.com

Competing interests: None declared.

1 Chapple A, Ziebland S, McPherson A. Stigma, shame, and blame experienced by patients with lung cancer: qualitative study. BMJ 2004;328:1470. (19 June.)

2 Beecham L. Smoking accepted on death certificates. BM 1992;305:543

\section{Internationally agreed strategy is needed on vaginal birth after caesarean}

EDITOR-The review by Guise et al concurs with other studies in showing that vaginal birth after caesarean section is harmful for fetus and mother, and repeated elective caesarean is not completely protective. ${ }^{1}$ Systematically interrogating the 160 cases of uterine rupture reported may have not only identified important predictive factors for uterine rupture but also highlighted the heterogeneity in clinical practice that clearly exists. Such differences in case selection and trial abandonment between healthcare providers probably helps to explain the unexpected 10 times greater perinatal mortality found in Scotland ${ }^{2}$ but not in the mainly US population based review by Guise et al.

The development of quality evidence based guidelines ${ }^{34}$ has been hampered by the absence of prospective clinical trials and reliance on retrospective observational data Their guidance has focused on ensuring that women are adequately counselled on the reasons and risks and benefits of accepting or declining the trial of vaginal birth after caesarean, but neglected to provide exact information on how labour should be conducted-particularly safe selection, induction and augmentation strategies. This may expose the guidelines to unfavourable critical appraisal and medicolegal challenge.

We therefore believe that prospective data collection through a central coordinating body and internationally agreed strategy should be initiated urgently. This body should have a dual role in reporting international observational data sets, and actively researching preventive strategies by conducting prospective clinical trials. Both these functions require a radical improvement in local or national data collection, standardising terminology (as stated by Guise et al), and willingness to collaborate in multicentre research.

Rajesh Varma MRC fellow in obstetrics and gynaecology r.varma@bham.ac.uk

Janesh K Gupta senior lecturer in obstetrics and gynaecology

j.k.gupta@bham.ac.uk

Birmingham Women's Hospital, Birmingham B15 2TG

Competing interests: None declared.

1 Guise JM, McDonagh MS, Osterweil P, Nygren P, Chan BK Helfand M. Systematic review of the incidence and consequences of uterine rupture in women with previous caesarean section. BMJ 2004;329:19-25.

Smith GC, Pell JP, Cameron AD, Dobbie R. Risk of perin tal death associated with labor after previous cesarean delivery in delivery in uncol

ACOG ACOG Practice Bulletin. Number 54 Vaginal bith after previous cesarean Obstet Ginecol. 2004:104.203-12 Nation Instinte for Clinical Excellence, Royal College of National Institute for Clinical Excellence, Royal College of Obstetricians and Gynaecologists. Caesarean section guidefor Wondon: NICE, 2004. (National Collaborating Centre Women's and Children's Health Clinical Guideline No 13.) www.nice.org.uk/page.aspx?o $=113190$ (accessed 21 Ju Interfacing between primary
and secondary care is needed

EDITOR-Straus et al highlighted the impact of severe acute respiratory syndrome (SARS) on professionalism and gave several examples of strained professional behaviour. ${ }^{1}$ Research in Hong Kong showed anxiety among general practitioners who, despite worries, demonstrated willingness to do their duty as was expected from a highly professional workforce. ${ }^{2}$ Altogether $82.3 \%$ of general practitioners in the study wanted more involvement in the management of SARS: $74.6 \%$ as educators and $68.4 \%$ as gatekeepers. ${ }^{3}$ However, the primary care system in Hong Kong is less well developed and most general practitioners work in the private sector, whereas most hospital care is given in the public sector, with little interfacing and collaboration. ${ }^{4}$

Primary care is the gatekeeper to hospital care. The fear and panic caused by SARS made it difficult for patients with symptoms to be managed in primary care without a close working relationship with and support system from hospitals. If general practition- ers had direct access to basic diagnostic procedures and communicated with the hospital team directly, they would have more confidence in screening out suspected cases. They can also be useful health educators to minimise panic, which would also decrease unnecessary admission.

Measures must be taken to avoid overloading the hospital system and putting further strain on frontline doctors in a public health crisis. This would ensure that professionalism was not eroded. General practitioners are useful partners but not fully used. In facing new public health challenges, governments should take the SARS crisis opportunity to strengthen the primary care system and ensure appropriate mechanisms for partnership and interfacing with secondary care. ${ }^{5}$

\section{Albert Lee professor}

alee@cuhk.edu.hk

William Wong assistant professor

Samuel Yeung Shan Wong assistant professor

Department of Community and Family Medicine,

Chinese University of Hong Kong, 4th Floor,

School of Public Health, Prince of Wales Hospital,

Shatin, Hong Kong

Kwong Ka Tsang health promotion officer

Centre for Health Education and Health

Promotion, School of Public Health, Chinese

University of Hong Kong

Competing interests: None declared.

1 Straus SE, Wilson K, Rambaldini G, Rath D, Lin Y, Gold WL. Severe acute respiratory syndrome and its impact on professionalism: qualitative study of physicians' behaviou during an emerging healthcare crisis. BMJ 2004;329:83-5. (10 July.)

2 Wong W, Lee A, Tsang KK, Wong S. How did general practitioners protect themselves, their staff and their families during the severe acute respiratory syndrome epidemic Hong Kong? J Epidemiol Community Health 2004;58:180-5. 3 Lee A., Wong W. Primary care during the SARS outbreak. BrJ Gen Pract 2003;September:733.

4 Lee A. Seamless health care for chronic diseases in dual health care system: managed care and role of family physihealth care system: managed care and
cians. J Manag Med 1998;12:398-405.

5 Lee A Abdullah ASM. Severe acute respiratory syndrome: challenge for public health practice in Hong Kong. Epidemiol Community Health 2003:57:655-8.

\section{Molluscum contagiosum is not always benign}

EDITOR-I welcome the informative clinical review on common skin infections in children by Sladden and Johnston. ${ }^{1}$ However, when a Molluscum contagiosum arises in eyelid skin or even at the eyelid margin, it is far from benign. The lesion causes chronic keratoconjunctivitis, which can be easily misdiagnosed and mistreated if the causative lesion is not identified. Vascular infiltration and scarring of the peripheral cornea can occur. ${ }^{2}$ I expect to see one or two children a year who have had a miserable few months with a sore, photophobic and discharging eye before referral to the eye clinic. Under such circumstances, I am sure that prompt treatment of the eyelid lesion is indicated and a short course of topical steroid drops may be helpful.

Richard M Redmond consultant ophthalmologist Scarborough Hospital, Scarborough YO12 6QL richard.redmond@acute.sney.nhs.uk

Competing interests: None declared.

\footnotetext{
1 Sladden MJ, Johnston GA. Common skin infections in 2 Kanski JJ. Clinical ophthalmology. 4th ed. Woburn, Md: 2 Kanski JJ. Clinical ophthalmology. 4t
Butterworth-Heinemann, 1999:62-3.
} 


\section{All drugs can have serious side effects}

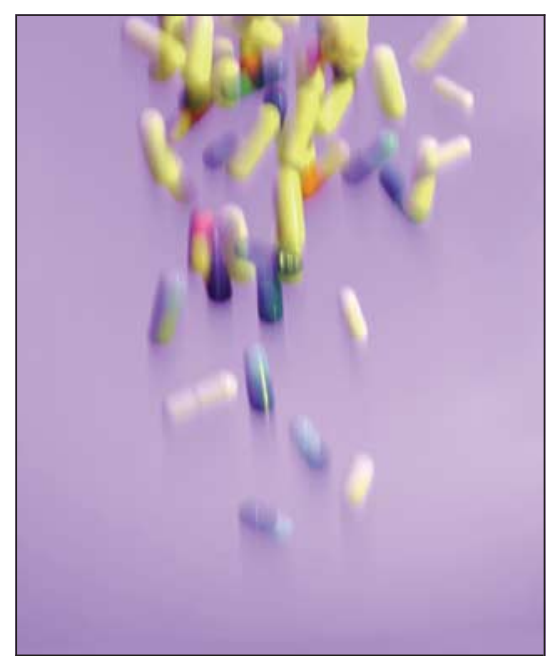

EDITOR-In their review article, Lee et al say that further evidence is required before atypical antipsychotics can be endorsed in the management of behavioural and psychological symptoms of dementia. ${ }^{1}$ Of the five randomised trials reviewed, only three contained information on adverse events, and only two of these reported on the number of serious adverse events.

Currently, no atypical antipsychotic is licensed for the treatment of behavioural disturbances in dementia. In March 2004, after analysing data from randomised placebo controlled clinical trials and finding approximately three times the risk of cerebrovascular adverse events in patients taking risperidone or olanzapine compared with placebo, the Committee on Safety of Medicines advised that risperidone or olanzapine should not be used for the treatment of behavioural symptoms of dementia. ${ }^{2}$ Perhaps this is all the evidence needed, but perhaps not. Let us not forget that all drugs can have serious side effects and that non-pharmacological interventions are important.

Anna V Richman specialist registrar in old age psychiatry

Mossley Hill Hospital, Liverpool L18 8BU

emileandanna@tinyworld.co.uk

Competing interests: None declared.

1 Lee PE Gill SS, Freedman M, Bronskill SE Hillmer MP, Rochon PA. Atypical antipsychotic drugs in the treatment Roch of behavioural and psychological symptoms of dementia: systematic review. $B M J$ 2004;329:75-8

Committee on Safety of Medicines. Atypical antipsychotic (CEM/CMO/2004/ 1.)

\section{Association of British \\ Pharmaceutical Industry's code of practice needs to be clarified}

EDITOR-The article by Eaton does not entirely reflect the requirements of the Association of the British Pharmaceutical Industry's code of practice for the pharmaceutical industry (www.pmcpa.org.uk). ${ }^{1}$ It is based on an editorial in the review of the code of practice from May, which reminded representatives that agreeing to give money in exchange for appointments with general practitioners would be a breach of the code. The Prescription Medicines Code of Practice Authority (which administers the code) occasionally receives reports of general practitioners' surgeries asking for a fee to see representatives. In such circumstances the authority writes to the general practitioners concerned, asking them to bear in mind the requirements of clause 15.3 of the code that no fee should be paid or offered for an interview. The authority was also aware of a surgery requesting that pharmaceutical company representatives paid a fee for what seemed to be a social event. No indication was given that there was any educational content. Representatives can reimburse surgeries for appropriate hospitality at meetings where the prime purpose is educational. This is specifically referred to in the supplementary information to clause 15.3 of the code. Meetings organised for groups of doctors and other health professionals that are wholly or mainly of a social or sporting nature are unacceptable. The purpose of the article in May's review of the code of practice was to remind companies of what is and what is not permitted under the code, and that unacceptable requests from health professionals can be forwarded to the authority for it to write to the surgeries concerned and ask that arrangements be changed.

Heather J Simmonds director

Prescription Medicines Code of Practice Authority, London SW1A 2 DY

hsimmonds@abpi.org.uk

\section{Competing interests: None declared.}

1 Eaton L. GPs asked not to demand payments from drug company representatives. $B M J$ 2004;429:72. (10 July.)

\section{The Portman Group does not represent alcohol industry}

EDITOR-I write with reference to Mayor's news item on a researcher, Robin Room, objecting to a representative from the drinks industry sitting on an alcohol research body. ${ }^{1}$ Room should check his facts before jumping to conclusions. Here are some facts.

Firstly, the Portman Group is not a trade association or lobby group. It does not represent the industry. It has no commercial purpose. Its role is to promote responsible drinking by the consumer and responsible marketing by producers.

Secondly, I was not nominated to the Alcohol Education and Research Council (AERC) by the industry or any industry related body. I was invited to apply by the Department for Culture, Media and Sport. I do not occupy one of the three places on the council that are traditionally reserved for industry nominees. This was made abundantly clear in discussions with the department and with the chairman of the council.
Thirdly, neither Robin Room nor anyone else engaged in alcohol research registered any concern when one of the industry representatives on the council was also the chairman of the Portman Group for two of the years he served on the council. His concern about the chief executive is therefore puzzling.

Fourthly, the Portman Group has co-funded a number of research projects with the Alcohol Education and Research Council in the past, at the invitation of the council, again without any apparent cause for concern.

Finally, all members of the Alcohol Education and Research Council are appointed as individuals and are committed as trustees to upholding the independence and integrity of the council. This I fully intend to do, whatever the source of any pressure.

Jean Coussins chief executive

Portman Group, London W1G 9DQ jcoussins@portmangroup.org.uk

Competing interests: None declared.

1 Mayor S. Researcher objects to drinks industry representative sitting on alcohol research body. BMJ 2004;329:71 (10 July.)

\section{Clinical examination has important role}

EDITOR-Threatened miscarriage is an excellent topic for your clinical review series, ${ }^{1}$ but it seems odd that Sotiriadis et al should almost entirely overlook the role of clinical examination, particularly in an article titled "evaluation and management." After a brief comment that thorough physical examination is essential to differentiate between genital and extragenital causes, the review moves directly from history to sonographic evaluation and maternal serum markers.

Many women with vaginal bleeding in early pregnancy present to primary and emergency services, where many of the investigations described in this review are not immediately available. The exact role and most appropriate type of physical examination is unclear, $^{2}$ and would be worthy of inclusion in an article intended for generalist readership.

To overlook physical examination as a key part of patients' assessment is contrary to one of the fundamental principles of medicine: even if the authors think that it has a small part to play this should be clearly stated, and the issues discussed.

Jonathan $\mathbf{R}$ Benger consultant in emergency medicine Academic Department of Emergency Care, United Bristol Healthcare Trust, Bristol, BS2 8HW

Jonathan.Benger@ubht.swest.nhs.uk

Competing interests: None declared.

Sotiriadis A, Papatheodorou S, Makrydimas G. Threatened miscarriage: evaluation and management. BMJ 2004; miscarriage: evalua

2 Hoey R, Allan K. Does speculum examination have a role in assessing bleeding in early pregnancy? Emerg Med J 2004;21:461-3. 